\title{
Psychophysiological Characteristics of Male Survivors of Myocardial Infarction
}

\author{
Anna I. Kodochigova, $\mathrm{PhD}, \mathrm{ScD}^{1^{*}}$; Viacheslav F. Kirichuk, $\mathrm{PhD}, \mathrm{ScD}^{1}$; \\ Mikhail S. Sinkeev ${ }^{1}$; Elena S. Olenko, $\mathrm{PhD}, \mathrm{ScD}^{1}$; Kseniia O. Belousova ${ }^{2}$; \\ Tatiana M. Bogdanova, $\mathrm{PhD}^{1}$; Galiia R. Shabanova ${ }^{1}$; Margarita D. Khazova ${ }^{1}$; \\ Kseniia V. Grigorieva ${ }^{1}$; Maxim A. Zankin ${ }^{1}$; Alexander S. Demin ${ }^{1}$

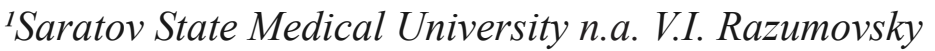 \\ ${ }^{2}$ The Ministry of Internal Affairs of the Russian Federation, Saratov Branch \\ Saratov, the Russian Federation
}

\begin{abstract}
The objective of this study was to analyze the psychophysiological personality characteristics of male survivors of myocardial infarction (MI) in order to identify the risks of recurrent cardiovascular events.

Material and Methods: We observed 60 male patients (mean age of 46.5 [38.7; 54.3]) diagnosed with ischemic heart disease (IHD) during outpatient and inpatient treatment. In the past (from one to three years ago), all of them suffered Q-wave MI (75\% - with localization in the posterior wall of the left ventricle, $25 \%$ - in the anteroseptal area). The psychological study included the following techniques and methods: the abridged MMMPI, the Spielberger-Khanin test, the TAS in the variant modified at V.M. Bekhterev Research Institute, S. Subbotin's STQ, E. Heim's technique for revealing individual coping strategies, and the projective psycho-geometric test.

Results: The discovered characteristics applicable to the psychological portrait of males with a history of MI (elevated levels of neuroticism and anxiety with elements of demonstrative behavior, complications in the expression of feelings and emotions) are a reflection of the psychosomatic radical component of IHD. This finding enables us to recommend including methods of psychological correction of discovered intrapersonal changes in the measures for preventing recurrent cardiovascular events in the studied cohort of patients.(International Journal of Biomedicine. 2019;9(1):19-22.)
\end{abstract}

Key Words: male patients $\bullet$ myocardial infarction $\bullet$ cardiovascular events $\bullet$ stress tolerance $\bullet$ coping behavior

\section{Abbreviations}

IHD, ischemic heart disease; MI, myocardial infarction; MMPI, Minnesota Multiphasic Personality Inventory; STAI, State-Trait Anxiety Inventory; STQ, Stress Tolerance Questionnaire; TAS, the Toronto Alexithymia Scale.

\section{Introduction}

According to the 2014 survey data, half of all fatal cases in the Russian Federation occurred due to cardiovascular diseases, while more than $80 \%$ of such cases are associated with IHD episodes, primarily MI. ${ }^{(1)}$ Among the numerous markers of increased risk of occurrence and complicated

*Corresponding author: Prof. Anna I. Kodochigova. PhD, ScD. Saratov State Medical University n.a. V. I. Razumovsky; the Russian Federation. E-mail: kodochigovaai@yandex.ru course of coronary pathology, the male gender is recognized as an independent factor. ${ }^{(2)}$ According to the Russian Federal Statistics Service, in 2016, the number of deaths caused by IHD per 100,000 of the working age population amounted to 123.6 men and 15.3 women. ${ }^{(3)}$

Currently, multicentric prospective studies have established the following independent risk factors for IHD and its complications: acute and chronic stress, hostility, heightened anxiety, depression, and alexithymia. ${ }^{(4-6)}$

Despite the significant number of works devoted to the study of the psychological portrait of MI survivors, research has 
not been conducted into their personal response characteristics in terms of protective and compensatory behavior with differentiation by spheres in combination with factors of stress tolerance, anxiety, alexithymia and classification of patient personalities.

In this regard, the objective of this study was to analyze the psychophysiological personality characteristics of male survivors of MI in order to identify the risks of recurrent cardiovascular events.

\section{Material and Methods}

We observed 60 male patients (mean age of 46.5 [38.7; 54.3]) diagnosed with IHD during outpatient and inpatient treatment. In the past (from one to three years ago), all of them suffered Q-wave MI (75\% - with localization in the posterior wall of the left ventricle, $25 \%$ - in the anteroseptal area), they received a full course of inpatient treatment and passed all stages of rehabilitation.

Inclusion criteria:

-Male gender

-Age from 30 to 55

- Confirmed IHD (stable angina CCS class I-III) in

patients with uncomplicated Q-MI

Exclusion criteria:

-Female gender

- Age over 55

- Cognitive impairments of various origins

- History of psychiatric treatment and observation

-History of psychoactive substances consumption

-Psychosomatic diseases as comorbid or competing pathologies

-Acute IHD forms registered in the last 90 days

- Untreated or uncontrolled arterial hypertension

- Chronic cardiac insufficiency stages II-III

-Acute forms of diseases

- Surgery in the last 90 days

- Oncological pathology

- Chronic diseases in the acute stage

The observed participants were in scheduled inpatient treatment in the cardiology department of the V.I. Razumovsky Saratov City Clinical Hospital №2, Saratov, Russia. The study was conducted in accordance with ethical principles of the WMA Declaration of Helsinki (1964, ed. 2013). Written informed consent was obtained from all participants.

Along with the clinical and physiological examinations, which included a list of mandatory methods of research (in accordance with the standards), the patients participated in a psychological study, which employed the following techniques and methods:

-The abridged MMMPI ${ }^{(7,8)}$ for determining basic

personality characteristics

-The Spielberger-Khanin test ${ }^{(9,10)}$

-The TAS in the variant modified at V.M. Bekhterev

Research Institute ${ }^{(11)}$

-S. Subbotin's STQ

•E. Heim's technique for revealing individual coping strategies with differentiation by cognitive, emotional, and behavioral spheres ${ }^{(12,13)}$

-The projective psycho-geometric test (S. Dellinger's test) modified by A.A Alekseyev and L.A. Gromova ${ }^{(14)}$ for express personality type evaluation.

Statistical analysis was performed using StatGraph Plus for Windows 6.0 software package. The normality of distribution of continuous variables was tested by the Kolmogorov-Smirnov test with the Lilliefors correction and Shapiro-Wilk test. For descriptive analysis, results are presented as mean \pm standard deviation (SD), median, interquartile range (IQR; 25th to 75th percentiles). Differences of continuous variables departing from the normal distribution, even after transformation, were tested by the Mann-Whitney $U$-test. The Wilcoxon criterion was used to compare the differences between the paired samples. Categorical variables were analyzed using the Chi-square test. A probability value of $P \leq 0.05$ was considered statistically significant.

\section{Results}

Results of the abridged MMPI are shown in Figure 1. The averaged MMPI scales profile shows a relative and peaked increase in T-cores on Hypochondriasis (1), Hysteria (3) and a peak tendency on Psychastenia (7) scales. Wherein, the lowest points of the profile are on the Depression (2), Psychopatic Deviate (4), and Hypomania scales (9). The "neuroticism triad" scale set transitions into the "conversion pentad."

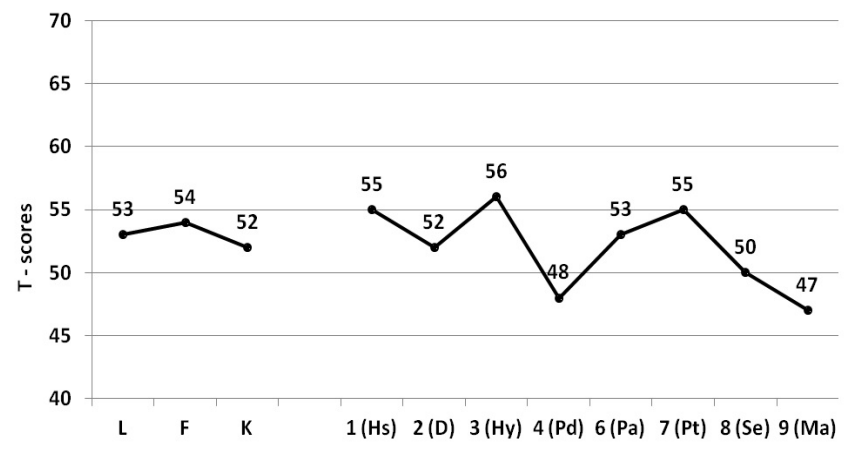

Fig. 1. Averaged profile of MMPI scales (T-Scores)

$L$ - Lie Scale, F - Infrequency or Feeling Bad Scale, $K-$ Correction Scale, 1 - Hypochondriasis, 2 - Depression, 3 - Hysteria, 4 - Psychopatic Deviate, 6 - Paranoia, 7 Psychastenia, 8 - Schizophrenia, 9 - Hypomania

Results of the Spilberger-Khanin test are shown in Figure 2. The state anxiety level in patients was at a low value (22.0 points), while trait anxiety, although average as judged by absolute values, still approached high levels (45.1 points).

The TAS results showed that the average level of alexithymia amounted to the score of 64.2 points, which belongs to the risk-band evaluation.

When determining the stress tolerance levels according to STQ (Fig.3), the majority of participants (61\%) showed average levels, while only $3 \%$ of examined individuals had low stress tolerance values $(P=0.04)$. 


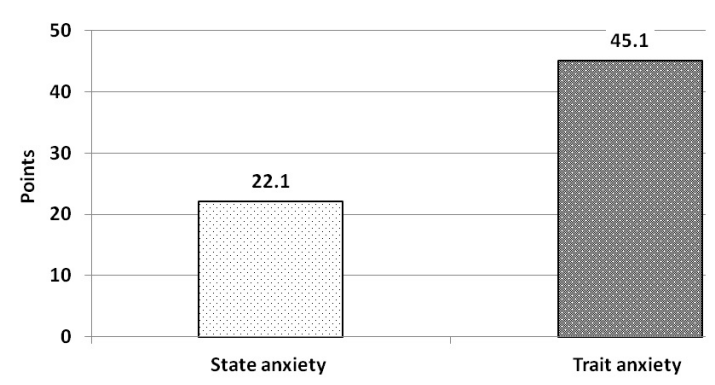

Fig. 2. Levels of state and trait anxiety according to the Spielberger-Khanin test (in point scores).

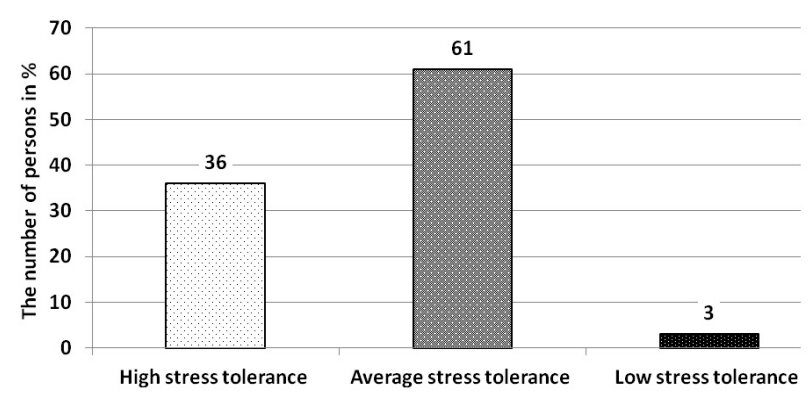

Fig. 3. Distribution of stress tolerance levels (\%).

Results of the Heim test are shown in Fig. 4. Thus, the adaptive reactions were dominant in all spheres of coping behavior $(P \leq 0.05)$. When further detailing the data of strategies for protective and compensatory behavior, it was found that problem analysis $(50 \%)$ was the dominant coping style in the cognitive sphere, while submission was the prevalent non-adaptive style. Optimism (82\%), among the adaptive coping reactions, dominated in the emotional sphere, while emotional suppression and self-incrimination were equally (40\%) prevalent among the non-adaptive approaches. When building the actual coping behavior patterns in participants, our attention was drawn to the prevalence of cooperation (56\%) as the adaptive coping form, while active avoidance (86\%) $(P \leq 0.05)$ was dominant among the non-adaptive reactions.

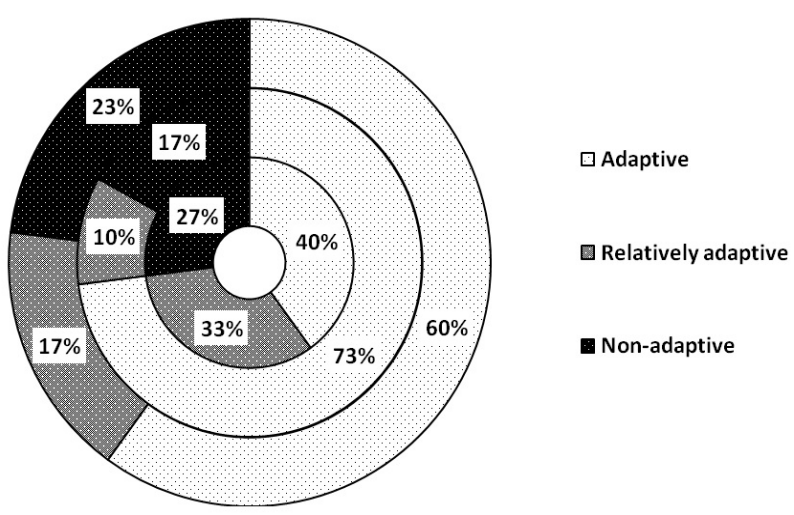

Fig. 4. Coping behavior strategies with differentiation by spheres. Inner ring - cognitive sphere, medium ring - emotional sphere, and outer ring - behavioral sphere.
According to the psycho-geometric test results with the stimulus material (Fig.5), the participants preferred the circle to other geometric shapes and rejected the zigzag figure with the same frequency $(47 \%)(P \leq 0.05)$.

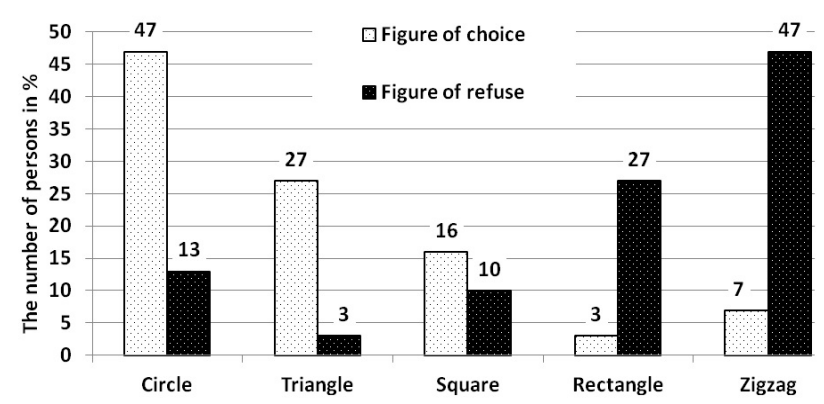

Fig. 5. Results of the psycho-geometric test.

\section{Discussion}

Based on the results of psychophysiological examination of male patients with a history of IM, they can be characterized as individuals with a tendency for increased levels of neuroticism and anxiety. In addition, the participants were characterized by conformity, strict adherence to social norms of behavior, a tendency to impose high standards on self and others combined with pessimistic assessment of their own capabilities and outcome of current events.

As a method of psychological protection, IHD patients with IM history tend to employ rationalization and intellectualization with elements of demonstrative behavior showing desire to acquaint others with their invented logical structures, which provides a possibility to force out, although not entirely, the oppressing anxiety and fear of recurrent acute cardiovascular events into the subconscious (relative increase on the MMPI Hypochondriasis and Hysteria scales with the transition of the "neuroticism triad" set of scales into the "conversion pentad" while retaining the tendency for peaked increase on the Psychastenia scale and having the lowest profile point on the Hypomania scale.

A combination of high levels of trait and low levels of state anxiety by the Spielberger-Khanin test may indicate active repression of high anxiety in order to "appear in positive light." This is supported by not only the characteristic tendency for demonstrative behavior (relative increase in MMPI T-scores on the Hysteria scale), but also by difficulties in understanding and expressing emotions and feelings (which is typical for alexithymia, by the observed levels of which the surveyed patients belong to the risk band).

The above is confirmed by the fact that, despite the preferential choice of adaptive forms of coping strategies in all spheres of stress-overcoming behavior (cognitive, emotional, and behavioral), almost two-thirds of the participants showed some decrease in stress tolerance (against the background of prevalence of adaptive coping styles in all three spheres by E. Heim's technique and the corresponding distribution 
of stress tolerance levels by the Subbotin Questionnaire). We would like to note that the obtained results on elevated neuroticism and anxiety levels in IHD patients are in line with the results of earlier studies. ${ }^{(15)}$ However, the available literature does not provide a detailed analysis of protective behavior in male survivors of MI (outlining the positive and negative sides of subsequent psychophysiological coping behavior patterns).

\section{Conclusion}

The discovered characteristics applicable to the psychological portrait of males with a history of MI (elevated levels of neuroticism and anxiety with elements of demonstrative behavior, complications in the expression of feelings and emotions) are a reflection of the psychosomatic radical component of IHD.

This finding enables us to recommend including methods of psychological correction of discovered intrapersonal changes in the measures for preventing recurrent cardiovascular events in the studied cohort of patients.

\section{Competing Interests} interests.

The authors declare that they have no competing

\section{References}

1. The Demographic Yearbook of Russia. Stat. sb. Rosstat, Moscow; 2015. ISBN 978-5-8947 6-414-6. [In Russian].

2. Boŭtsov SA, Samorodskaia IV. [Dynamics of cardiovascular mortality among men and women in subjects of Russian Federation (2002 to 2011)]. Kardiologiia. 2014;54(4):4-9. [Article in Russian].

3. Boytsov SA, Deev AD, Shalnova SA. [Mortality and risk factors for non-communicable diseases in Russia: Specific features, trends, and prognosis]. Ter Arkh. 2017;89(1):5-13. doi: 10.17116/terarkh20178915-13. [Article in Russian]. 4. Ageenkova E.K. Arbitrary prolongation of psychoemotional stress as a risk factor for cardiovascular diseases) [Electronic publication]. Personality in a Changing World: Health, Adaptation, Development. 2016;4(15). [Article in Russian].

5. Chida Y, Steptoe A. The association of anger and hostility with future coronary heart disease: a meta-analytic review of prospective evidence. J Am Coll Cardiol. 2009;53(11):936-46. doi: 10.1016/j.jacc.2008.11.044.

6. Isaeva ER. Coping behavior and psychological protection of the individual in the health and illness conditions. SPb GMU; 2009. ISBN 978-5-88999-069-7. [In Russian].

7. Zaitsev VP. [Mini-Mult psychological test version]. Psikhologicheskiy Zhurnal. 1981;2(3):118-23. [Article in Russian]. 8. Zaĭtsev VP, Aĭvazian TA. [Psychological AMPI test: application in clinical medicine (analytical review)]. Ter Arkh. 2008;80(4):89-92. [Article in Russian].

9. Karandashev VN, Lebedev MS, Spielberger CD. Evaluation of anxiety: a guide to use. St. Petersburg; 2004. [In Russian].

10. Khanin YL. A brief guide to the use of a scale of reactive and personal anxiety by Ch.D. Spielberger. Leningrad.: LNII FC; 1976. [In Russian].

11. Isurina GL, Kaydanovskaya EV, Karvasarsky BD. Alexithymia and methods of determination thereof in allied psychosomatic disorders: Method, textbook, St. Petersburg; 1994. [In Russian].

12. Heim E. [Coping and psychological adaptation: is there appropriate and inappropriate coping?]. Psychother Psychosom Med Psychol. 1988;38(1):8-18. [Article in German].

13. Karademas EC, Tsalikou C, Tallarou MC. The impact of emotion regulation and illness-focused copying strategies on the relationship of illness-related negative emotions to subjective health. J Health Psychol. 2011;16(3):510-9. doi: 10.1177/1359105310392093.

14. Dellinger S. Psychogeomtrics. Psychogeomtrics: How to Use Geometric Psychology to Influence People. New Jersey: Prentice-Hall; 1989.

15. Smulevich AB. Psychosomatic disorders in clinical practice. In: Smulevich AB, editor. MEDpress-inform, Moscow; 2016. ISBN 978-5-00030-295-8. [In Russian]. 